\title{
Impact factors of soil wind erosion in the center of Taklimakan Desert
}

\author{
Qing $\mathrm{HE}^{1,2^{*}}$, XingHua YANG ${ }^{1,2}$, Ali Mamtimin ${ }^{1,2}$, ShiHao TANG ${ }^{3}$ \\ ${ }^{1}$ Istitute of Desert Meteorology, China Meteorological Administration, Urumqi 830002, China; \\ ${ }^{2}$ Desert Atmosphere and Environment Observation Experiment of Taklimakan Station, Tazhong 841000, China; \\ ${ }^{3}$ National Satellite Meteorological Center, China Meteorological Administration, Beijing100081, China
}

\begin{abstract}
The development and progress of soil wind erosion are influenced by the factors of climate, terrain, soil and vegetation, etc. This paper, taking Tazhong region, a town in the centre of the Taklimakan Desert, as an example and using comparative and quantitative methods, discussed the effects of climate, surface roughness (including vegetation cover) and surface soil properties on soil wind erosion. The results showed that the climate factor index $C$ of annual wind erosion is 28.3, while the maximum of $C$ is 13.9 in summer and it is only 0.7 in winter. The value of $C$ has a very good exponential relationship with the wind speed. In Tazhong region, the surface roughness height is relatively small with a mean of $6.32 \times 10^{-5} \mathrm{~m}$, which is in favor of soil wind erosion. The wind erosion is further enhanced by its sandy soil types, soil particle size, lacking of vegetation and low soil moisture content. The present situation of soil wind erosion is the result of concurrent effects of climate, vegetation and surface soil properties.
\end{abstract}

Keywords: Taklimakan Desert; roughness; particle size; soil moisture content; soil wind erosion

\section{Introduction}

Wind erosion is the detachment, transportation and re-deposition of soil particles by wind. The result of wind erosion on agricultural soil is the loss of topsoil and nutrients, therefore, reduces crop yield. In arid and semi-arid region, wind erosion is one of the major reasons for land desertification. A sparse vegetation cover, a loose, dry and smooth soil surface, and strong winds all increase the risk of soil wind erosion. The mechanics and influencing factors of wind erosion have been investigated by many people for a long time. A semi-empirical equation for estimating wind erosion on soil was established by Woodruff et al. (1965). In this equation, the dust emission by wind erosion on a surface was expressed as the functions of soil erodibility, surface roughness, climatic factor, the length of farming field in the prevail wind direction and vegetation coverage. However, Gillette et al. (1988) suggested that the dust emission by wind erosion could be expressed as the function of wind speeds and the surface conditions. In another study, all the influencing factors of wind erosion were categorized as weather and climate conditions, soil conditions, surface roughness, soil utilization and management practices (Shao et al., 1997). He et al. (1997) carried out a preliminary simulation test on the influencing factors of wind erosion in wind tunnel. The tested factors included wind regimes, soil surface cover conditions, surface material composition and human factor. Some scholars investigated the wind regime in Tazhong region and explored the relationship between wind speed and sand transport rate (Zhao et al., 1995; Wang et al., 2001; $\mathrm{Zu}$ et al., 2005). These studies, however, only took wind speed into account for wind erosion, lacking of a comprehensive analysis of all factors on wind erosion. This paper discussed the influences of climate, surface roughness (including vegetation cover) and surface soil properties on the wind erosion in Tazhong region.

\section{Study area and data analysis}

The study area is selected at Tazhong, where has a

Received 2010-09-29, accepted 2010-10-26

doi: 10.3724/SP.J.1227.2011.00009

* Corresponding author: Qing HE (E-mail: qinghe@idm.cn) 
bare sand surface with serious wind erosion in the Taklimakan Desert (Fig.1). Spring and summer are windy seasons in this area. Wind combined with bared surface and low soil moisture frequently produces massive dust storms. The sand and dust storm weather occurs more than 200 days every year. The sand and dust storms bring many problems to local oil works. Also, those sand and dust storms produce a huge amount of dust aerosol, which may have a deep influence on regional and even global climate.

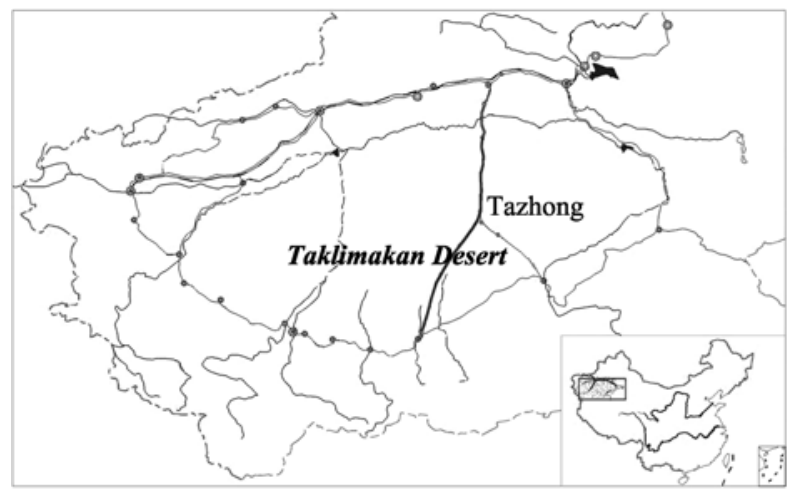

Fig. 1 The location of Tazhong region in the Taklimakan Desert

A long term weather station is run in Tazhong by the Desert Atmosphere and Environment Observation Experiment Station of Taklimakan Desert $\left(83^{\circ} 40^{\prime} \mathrm{E}\right.$, $39^{\circ} 00^{\prime} \mathrm{N}$, and $1,099.3 \mathrm{~m}$ a. s. 1.). All data used in this study, including local meteorology, land surface characters, and land surface process (turbulence characteristic, parameter of soil erosion and dust emission and transportation), are provided by the research station.

\section{Results and discussion}

\subsection{The role of climate factors on soil wind erosion}

Climate factors play important roles in soil wind erosion. During the process of land desertification, a dry and windy climate is essential. The climate factors mainly include wind regime, precipitation, temperature, and humidity, among which wind speed is the primary factor because it is the most direct power source of soil wind erosion. The larger the wind speed is, the greater the erosion will be. Temperature and precipitation are also important factors affecting soil wind erosion. These two factors determine the drought degree of a region, and a drier soil is more feasible for wind erosion. Therefore, in evaluating the wind ero- sion potential of an area, the climate factors should be firstly taken into account in the evaluation process. Here, the equation recommended by FAO (1979) for calculating wind erosion potential was revised (Equation 1) and tested in Tazhong area.

$$
C=\frac{1}{100} \sum_{i=1}^{12} u^{3}\left(\frac{E T P_{i}-P_{i}}{E T P_{i}}\right) d .
$$

Where $u$ is monthly average wind speed observed at $2 \mathrm{~m}$ height $(\mathrm{m} / \mathrm{s}) ; E T P_{i}$ is monthly evaporation potential $(\mathrm{mm}) ; P_{i}$ is monthly average precipitation $(\mathrm{mm}) ; d$ is the number of days in a month. ETP $P_{i}$ can be calculated by the equation which is given by Cheng et al. (1980):

$$
\operatorname{ETP}_{i}=0.19\left(20+T_{i}\right)^{2}\left(1-r_{i}\right) .
$$

Where $T_{i}$ is monthly average temperature; $r_{i}$ is monthly average relative humidity.

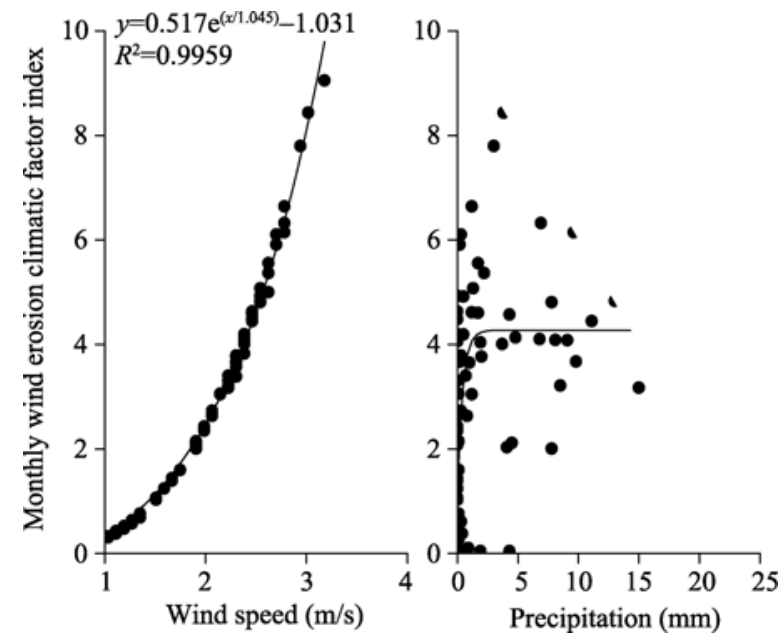

Fig. 2 The relationships of climatic factor index for monthly wind erosion with wind speed and precipitation in Tazhong region during the period of 1999-2008

Based on the data from 1999 to 2008 and Eqs. (1), and (2), the climate factor index $(C)$ of the annual wind erosion was 28.3 in Tazhong region, which indicates that climate erosion ability was not strong. This is consistent with the result obtained by Dong et al. (1994). The value of $C$ is high in summer (13.9), followed by spring and autumn, which is 9.9 and 3.8 respectively, and it is only 0.7 for winter. The relationships between the climate factor index of wind erosion $(C)$, and monthly average wind speed and monthly precipitation in Tazhong were analyzed (Fig. 2). The results showed that $C$ had a very good exponential 
relationship with wind speed with the correlation coefficient $\left(R^{2}\right)$ of 0.9959 . Its value becomes higher when wind speed increases. The $C$ value, however, does not closely relate to precipitation, which implies that precipitation in Tazhong plays a less important role on wind erosion than wind speed does.

\subsection{Surface roughness}

Surface roughness $\left(Z_{0}\right)$ is an important physical parameter related to land surface erosion. It means a height where the average wind speed decreases to zero. For a fixed location, the surface roughness $Z_{0}$ is often considered a constant if the surface properties had not changed (Wu, 1987). Its value varied depending on the terrain undulation, vegetation coverage and other factors. To some extent, the increase of surface roughness could control soil wind erosion, suppress blowing sand and improve ecological environment (Fryear, 1985). Thus, the surface roughness is one of the important factors for accessing soil wind erosion potential.

\subsubsection{Vegetation coverage of surface}

Vegetation coverage could change the surface roughness and affect wind speed. On the other hand, it could make the soil particles combine more tightly near the root zone and prevent them from wind force detachment. Raupach (1993) provided the following equation to evaluate the role of vegetation coverage on wind erosion:

$$
R(\lambda)=\left\{\begin{array}{ll}
1 & \lambda=0 \\
\sqrt{(1-m \sigma \lambda)(1+m \beta \lambda)} & \lambda>0
\end{array} .\right.
$$

Where $R(\lambda)$ is the index of vegetation coverage contribution to wind erosion; $\sigma$ is ratio of the root area and the plain area, with an empirical value of $1.45 ; \beta$ and $m$ are also empirical values with the value of 202 and 0.16 respectively; $\lambda$ is shear area index of vegetation and determined by cover fraction of vegetation. It can be calculated by the empirical formula (Shao et al., 1997):

$$
\lambda=\left\{\begin{array}{ll}
0 & f=1 \\
-0.35 \ln (1-f) & f<1
\end{array} .\right.
$$

In the centre of Taklimakan Desert, vegetation is sparse and has a simple community structure. Except for the oilfield operation area, living area and both sides of the desert highway, the ground surface of TaZong region is almost bare. Therefore, the shear area index $\lambda$ of vegetation is approximately zero, and the value of $R(\lambda)$ is 1 . Thus the effect of vegetation on the soil wind erosion is considered to be zero.

\subsubsection{The surface roughness of Tazhong}

Based on the wind tunnel experiment and field research work, Bagnold (1941) gave the equation of velocity distribution with height:

$$
u=5.75 u_{*} \lg \frac{Z}{Z_{0}} .
$$

Where $u$ is the wind speed $(\mathrm{m} / \mathrm{s}) ; u_{*}$ is the friction velocity $(\mathrm{m} / \mathrm{s}) ; Z$ is the observation height $(\mathrm{m}) ; Z_{0}$ is the surface roughness $(\mathrm{mm})$. After rearranging equation (5), the following equation could be obtained:

$$
\lg Z_{0}=\frac{u_{1} \lg Z_{2}-u_{2} \lg Z_{1}}{u_{1}-u_{2}} .
$$

Based on Eq. 6, if we know the wind speeds of two different heights, the surface roughness can be calculated. The data from April 1, 2007 to August 31, 2007 recorded by two automatic weather stations (one is located in flat sand land and the other is located in the tops of tall dune-chains in Tazhong area) were used to calculate $Z_{0}$ and obtained an average value of $5.11 \times 10^{-5} \mathrm{~m}$ in flat sand land, and $7.53 \times 10^{-5} \mathrm{~m}$ at the top of big dune-chains. The two values were averaged to get the average surface roughness height, which is $6.32 \times 10^{-5} \mathrm{~m}$ in Tazhong region. This value is closed to the value of flat sand in Mu Us Desert (Mei et al., 2006).

Table 1 showed the wind tunnel test results of wind erosion modulus of various surfaces at different wind speeds (Liu et al., 2000). From Table 1, we can see that the wind erosion ability became bigger when the surface roughness height became smaller. Using Table 1 , we have analyzed the relationship between surface roughness height and wind erosion modulus and calculated the wind erosion modulus of Tazhong region at different wind speeds. The results showed that the wind erosion modulus of Tazhong region was bigger than those of other regions at the same wind speed. So the relative small surface roughness height has actually aggravated the wind erosion in Tazhong region.

\subsection{Land surface properties}

Physicochemical properties of surface soil have a significant influence on the occurrence and development of wind erosion. This paper analyzed the effects of soil types, soil particle size and soil water content on wind erosion. 
Table 1 The relationship between roughness length and the amount of wind erosion

\begin{tabular}{|c|c|c|c|c|c|c|}
\hline \multirow{2}{*}{ Sampling area } & \multirow{2}{*}{$\begin{array}{l}\text { Roughness } \\
\text { (m) }\end{array}$} & \multicolumn{5}{|c|}{ Wind erosion modulus at different wind speeds $\left(\mathrm{kg} /\left(\mathrm{m}^{2} \cdot \mathrm{h}\right)\right)$} \\
\hline & & 8 & 10 & 15 & 20 & 25 \\
\hline Grassland & $1.42 \times 10^{-3}$ & -6.022 & 0.483 & 6.995 & 13.058 & 23.692 \\
\hline Cultivated land & $6.30 \times 10^{-4}$ & 0.932 & 12.221 & 30.855 & 39.603 & 58.630 \\
\hline Sand land & $1.83 \times 10^{-4}$ & 20.704 & 51.504 & 103.611 & 147.918 & 239.070 \\
\hline$\sum$ Tazhong & $6.32 \times 10^{-5}$ & 31.814 & 75.280 & 145.817 & 219.634 & 371.910 \\
\hline
\end{tabular}

\subsubsection{Types of surface soil}

Soil erosion is related to the regional geological environment and is affected by the soil texture (Jilili et al., $2002,2010)$. Soils with various textures have different water contents, water retention, gummy cohesion and plastic pressure of soil particles. Accordingly, under the same wind speed, the degrees of soil erosion are different for different soils. Based on the soil classification of the U.S. Department of Agriculture, sandy clay, loam and clay are categorized according to the percentages of sand, silt and clay in the soil (Shao et al., 2001). Without considering other factors, loam soil is more easily eroded by wind than clay soil, while sandy clay soil is most easily eroded. Lu et al. (1999) and Shao et al. (2001) have studied the plasticity of various soils. The results showed that the horizontal component of the plastic pressure (Ps) of the sandy clay soil usually was 20 , while the Ps of loam was only 0.5 and that of clay was 350 . Ps is a physical parameter which represents the soil erodibility and is determined by the soil density. Soils with textures such as sandy clay and loam have a small Ps and big erodibility. Compact soil has a relatively larger Ps and smaller erodibility. According to the particle-size distribution of the surface soil in Tazhong region, the soil is sandy clay which is loose, ventilatory and permeable. This type of soil has large pore space among particles. In addition, they lack plasticity, cohesive property and sticking tendency. The strong wind credibility combined with this easy eroded soil makes Tazhong a strong wind erosion region (Li et al., 2006; Wang et al., 2006; Wu et al., 2006).

\subsubsection{Particle size of surface soil}

Soil particle size also has the effect on wind erosion. The larger the particle size is, the more energy will be needed to move soil particles and, therefore, the chance of wind erosion occurs. Table 2 showed the particle size parameters of some soil samples taken from the Tazhong region. The 17 samples were collected either from dunes or the land between dunes. Most samples have the particle sizes ranging from 100 $\mu \mathrm{m}$ to $250 \mu \mathrm{m}$ that belong to fine sand. Only the particle size of the sample No.17 is less than $100 \mu \mathrm{m}$ that belongs to very fine sand. The average particle size is $136 \mu \mathrm{m}$. According to the formulas of threshold velocity which was given by Shao et al. (2000), we calculated the starting velocities of different sands in the Tazhong (Fig. 3). The smaller the particle size is, the stronger the inner viscous force will be, and this increases the threshold fraction velocity $\mathrm{u}_{*}$. $\mathrm{u}_{*_{\mathrm{t}}}$ has a minimum value about $0.24 \mathrm{~m} / \mathrm{s}$ when the particle size is $100 \mu \mathrm{m}$. When the particle size increases, the inner viscous force decreases gradually and the gravity increases gradually at the same time. The average particle size of the sand in Tazhong region is $136 \mu \mathrm{m}$, which is close to the size that has the smallest starting velocity. This indicates that, in the aspect of sand size,

Table 2 The particle size parameters of surface soil in Tazhong region

\begin{tabular}{ccccc}
\hline $\begin{array}{c}\text { No. of } \\
\text { sample }\end{array}$ & $\mathrm{Mz}(\mu \mathrm{m})$ & $\sigma$ & $\mathrm{SK}_{1}$ & $\mathrm{KG}$ \\
\hline 1 & 132 & 0.69 & 0.05 & 0.99 \\
2 & 142 & 0.49 & 0.01 & 0.96 \\
3 & 145 & 0.58 & 0.00 & 0.94 \\
4 & 140 & 0.51 & 0.02 & 0.97 \\
5 & 154 & 0.54 & 0.01 & 0.95 \\
6 & 136 & 0.59 & 0.00 & 0.94 \\
7 & 161 & 0.72 & 0.11 & 0.97 \\
8 & 152 & 0.61 & 0.00 & 0.94 \\
9 & 137 & 0.48 & 0.00 & 0.96 \\
10 & 129 & 0.54 & 0.01 & 0.95 \\
11 & 136 & 0.48 & 0.00 & 0.96 \\
12 & 144 & 0.48 & 0.01 & 0.96 \\
13 & 130 & 0.62 & 0.02 & 0.94 \\
14 & 131 & 0.47 & 0.00 & 0.96 \\
15 & 126 & 0.47 & 0.00 & 0.96 \\
16 & 123 & 0.42 & 0.00 & 0.96 \\
17 & 99 & 0.70 & 0.08 & 1.04 \\
\hline & & & &
\end{tabular}




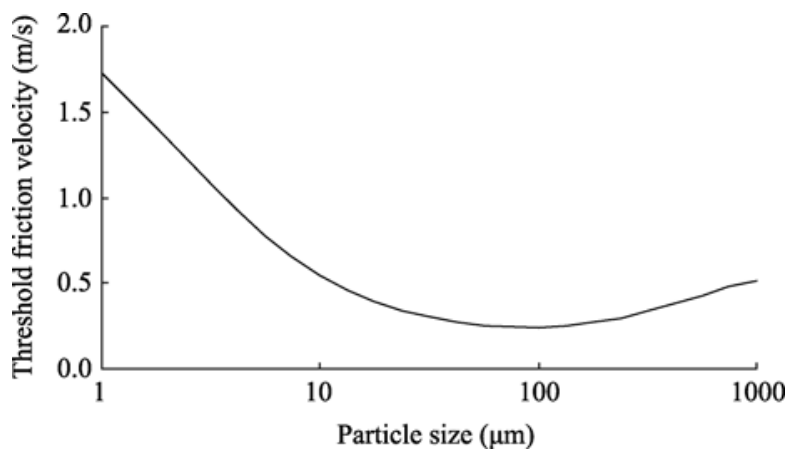

Fig. 3 The variations of threshold friction velocity with particle size in Tazhong region

Tazhong region is more easily to suffer from wind erosion and the intensity of wind erosion is stronger than other regions under the same wind speed.

\subsubsection{Moisture content of surface soil}

Moisture content of surface soil is also an important factor to affect soil wind erosion. Regional soil moisture depends on precipitation, evaporation and soil water retention in the region. If soil is humid, the viscosity of soil would increase and aggregation between soil particles be enhanced, and then the critical friction velocity, windblown sand speed and sand transport rate would be changed. Fecan et al. (1999) and Dong et al. (2002) have carried out a lot of works in this field and established the equations:

$$
\begin{gathered}
\begin{cases}H(w)=1 & w \leq w^{\prime} \\
H(w)=\sqrt{1+a\left(w-w^{\prime}\right)^{b}} & w>w^{\prime}, \\
w^{\prime}=0.0014(\text { clay } \%)^{2}+0.17(\text { clay } \%)\end{cases} \\
H(w)=\sqrt{1+k w} .
\end{gathered}
$$

Where $H(w)$ is an index that represents the effect of soil moisture on wind erosion; $w$ is volumetric water content of surface soil (\%o); $w^{\prime}$ is critical value; $a$ and $b$ are empirical constants whose values depend on soil type; clay $\%$ is the percentage of clay in soil; $k$ is proportional coefficient with value ranging from 1.5 to 3.0. Shao et al. (2001) has given the values of $w^{\prime}, a$ and $b$ to various soils based on the research on Fecan et al. (1999). In those values, the critical value of sandy soil's moisture was the smallest, only 5\%o while the critical value of clay was the biggest, $17 \%$. This indicates that in the process of wind erosion, the response of sandy soil to the water content is very sensitive.

Figure 4 shows the soil moisture contents at $5 \mathrm{~cm}$ and $10 \mathrm{~cm}$ depths of a soil profile in Tazhong region from January to August of 2008. The soil moisture contents at $5 \mathrm{~cm}$ and $10 \mathrm{~cm}$ depths from January to March were relatively higher than that in other times. From January to March, the soil moisture content at 5 $\mathrm{cm}$ depth was about $0.4 \mathrm{~g} / \mathrm{kg}$ while from April to August it was near 0 . The maximum of $10 \mathrm{~cm}$ depth soil moisture content appeared in March, which was 9.49 $\mathrm{g} / \mathrm{kg}$. From April to August the soil moisture content at $10 \mathrm{~cm}$ depth was lower than $8 \mathrm{~g} / \mathrm{kg}$. On average, the soil moisture contents at $5 \mathrm{~cm}$ and $10 \mathrm{~cm}$ depths were lower than $5 \mathrm{~g} / \mathrm{kg}$ from January to August. Tazhong region is dominated with sandy soil, so the value of $w$, is $5 \mathrm{~g} / \mathrm{kg}$, which is larger than the mean value of soil moisture contents at $5 \mathrm{~cm}$ and $10 \mathrm{~cm}$ depths. Based on the Eqs. (7) and (8), we obtained $H(w)$ of 1, which indicated the effect of moisture content on wind erosion can be neglected.

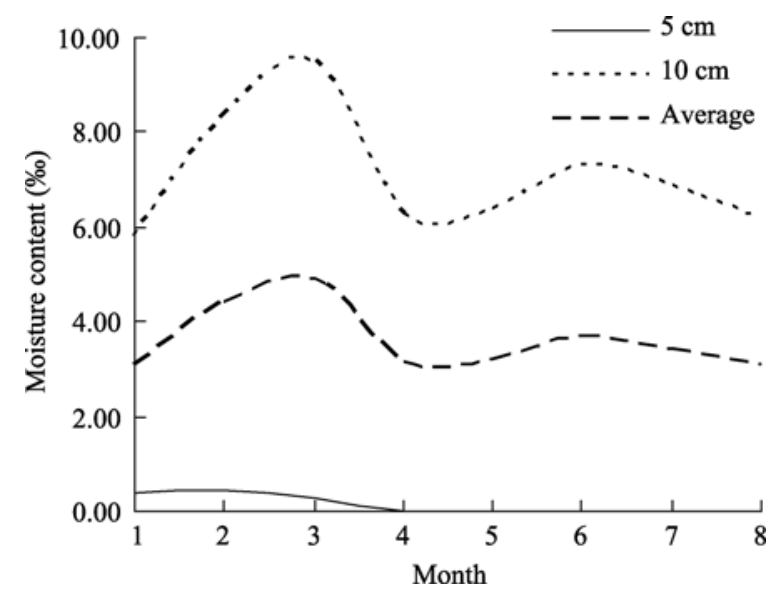

Fig. 4 The moisture content of surface soil in Tazhong region from January to August of 2008

\section{Other impact factors}

Based on the wind-tunnel test, Nickling (1981) suggested that the content of soil salt in ground surface also had an effect on wind erosion. Soil hardness is factor compacting wind erosion. Now, there is no good method for determining the soil hardness value, and it was given 1 during a study on wind erosion by Shao et al. (2001).

\section{Conclusions}

The purpose of this paper was to analyze the factors 
compacting soil wind erosion in Tazhong region. By analyzing the climate factor index, we found that the wind erosion contributed from climate factor was not big in Tazhong region. The climatic factor index has a very good exponential relationship with wind speed, and its value became larger when wind speed increased. The climate factor index negatively related to precipitation, but the relation was not strong.

Our research indicated that, in Tazhong region, the average surface roughness height, $Z_{0}$, is only $6.32 \times 10^{-5}$ $\mathrm{m}$, indicating a surface that was more erodible.

The soil in Tazhong region is loose and lack of plasticity and cohesiveness and those properties make it easily be eroded by wind. The average particle size of the soil in Tazhong region is close to the size in which the lowest starting velocity occurs, and this in-

\section{References}

Bagnold R A. 1941. The physics of blown sand and desert dune. New York: Methuen, 39-98.

Chen T W. 1980. Determination and Calculation Method of Field Evaporation and Evaporation Power. Geographical Bulletin, No.12. Beijing: Science Press.

Dong Y X, Kang G D. 1994. Study on the wind erosion climatie erosivity in arid and semi-arid areas in China. Journal of Soil Land Water Conservation, 8(3): 1-7.

Dong Z B, Liu X, Wang H, et al. 2002. The flux profile of a blowing sand cloud: a wind tunnel investigation. Geomorphology, 49: 219-230.

FAO. 1979. A Provisional Methodology for Soil Degradation Assessment. Rome: FAO, 61-63.

Fecan F, Marticorena B, Bergametti G. 1999. Parameterization of the increase of the aeolian erosion threshold wind friction velocity due to soil moisture for arid and semi arid areas. Annales Geophysicae, 17: 149-157.

Fryear D W. 1985. Transactions of the ASAE, 28(3): 781.

Gillete D A, Passi R. 1988. Modeling dust emission caused by wind erosion. Journal of Geophysical Research, 93: 14234-14242.

He D L, Zhou B G, Li C Z, et al. 1986. Preliminary study on the physical process of ground surface erosion in wind tunnel. Journal of Desert Research, 6(1): 25-31.

Jilili Abduwaili, Mu G J. 2002. Analysis on the dust storms and their disasters in the lakebed region of Ebinur lake, Xinjiang. Arid Land Geography, 25(2): 149-154.

Jilili Abduwaili, Liu D W, Wu G Y. 2010. Saline dust storms and their ecological impacts in arid regions. Journal of Arid Land, 2(2): $144-150$.

Li X L, Shen X D, Zang Y J. 2006. Experimental analysis on soil wind-erosion amount in Siziwang Banner North Yinshan Mountain, Iner Mongolia. Arid Land Geography, 29(2): 292-296.

Liu M Y, Dai Q H, Zhang L H, et al. 2000. Analysis on dynamic factors of soil wind erosion in sandy land. Soil and Water Conservation in China, 7: 28-30. dicates that the power which needs to move the sand here is small comparing with those of other places. The moisture content of surface soil is very low. The mean values at $5 \mathrm{~cm}$ and $10 \mathrm{~cm}$ depths in Tazhong were lower than $5 \mathrm{~g} / \mathrm{kg}$ from January to August, which resulted in a low viscosity between soil particles and made soil more erodible. The present situation of soil wind erosion is the result of concurrent effects of climate, vegetation and surface soil properties.

\section{Acknowledgements}

This work was funded by the National key Technology R \& D Program (2008BAC40B05-01), the National Natural Science Foundation of China (40775019), and Xinjiang Uygur Autonomous Region Science and Technology Key Project (200833119).

Lu H, Shao Y P. 1999. A new model for dust emission by saltation bombardment. Journal of Geophysical Research, 104: 1682716842.

Mei F M, Rajot J, Alfaro S, et al. 2006. The changes and physical meaning of aerodynamic roughness length on level sand ground. Progress in Natural Science, 16(3): 325-330.

Nickling W G, Ecclestone M. 1981. The effects of soluble salts on the threshold shear velocity of fine sand. Sedimentology, 28: 505-510.

Raupach M R. 1993. Dry deposition of gases and particles to vegetation. Clean Air, 27: 200-203.

Shao Y, Lance M L. 1997. Wind prediction erosion over the Australian continent. Journal of Geophysical Research, 102: 30091-30105.

Shao Y, Lu H. 2000. A simple expression for wind erosion threshold friction velocity. Journal of Geophysical Research, 105: 22437-22443.

Shao Y. 2001. A model for mineral dust emission. Journal of Geophysical Research, 106: 20239-20254.

Wang X M, Dong Z B, Chen G T, et al. 2001. Characteristics of blown sand environment in middle Taklimakan Desert. Journal of Desert Research, 21(1): 56-61.

Wang L B, Hu X L, Yu W L, et al. 2006. Spatial heterogeneity of granule diameter and its relation with shrub size and soil erosion. Arid Land Geography, 29(5): 688-693.

Woodruff N P, Siddoway F H. 1965. A wind erosion equation. Soil Science Society Proceedings, 602-608.

Wu S L, Li Z Z, Hui J, et al. 2006. Study on the distribution character of surface pressure of nabkhain wind-tunnel imitative experiment. Arid Land Geography, 29(6): 790-793.

Wu Z. 1987. Blown Sand Physiognomy. Beijing: Science Press, 20-28, $172-173$

Zhao J F, Li C S, He Q, et al. 1995. Analysis on sand-moving wind and estimation of sand transport in the Hinterland of Taklimakan Desert. Arid Land Geography, 18(3): 39-47.

Zu R P, Zhan K C, Qu J J, et al. 2005. The intensity of sand-drift activities in Taklimakan Desert. Geographical Research, 24(5): 699-707. 